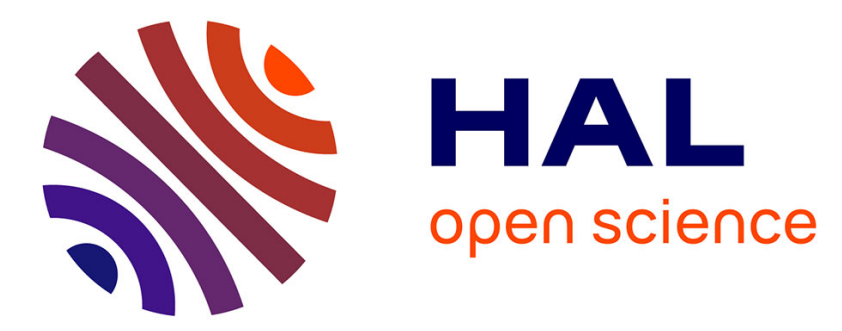

\title{
Selective laser melting of tungsten carbide reinforced maraging steel composite
}

Nan Kang, Wenyou Ma, Lorene Heraud, Mohamed El Mansori, Fuhai Li, Min Liu, Hanlin Liao

\section{- To cite this version:}

Nan Kang, Wenyou Ma, Lorene Heraud, Mohamed El Mansori, Fuhai Li, et al.. Selective laser melting of tungsten carbide reinforced maraging steel composite. Additive Manufacturing, 2018, 22, pp.104110. 10.1016/j.addma.2018.04.031 . hal-02355643

\section{HAL Id: hal-02355643 https://hal.science/hal-02355643}

Submitted on 16 Sep 2020

HAL is a multi-disciplinary open access archive for the deposit and dissemination of scientific research documents, whether they are published or not. The documents may come from teaching and research institutions in France or abroad, or from public or private research centers.
L'archive ouverte pluridisciplinaire HAL, est destinée au dépôt et à la diffusion de documents scientifiques de niveau recherche, publiés ou non, émanant des établissements d'enseignement et de recherche français ou étrangers, des laboratoires publics ou privés. 


\section{Selective laser melting of tungsten carbide reinforced maraging steel composite \\ KANG, Nan ${ }^{\text {abc; }}$ MA, Wenyou; HERAUD, Lorene ${ }^{\mathrm{a}}$; EL \\ MANSORI ${ }^{\mathrm{a}}$, Mohamed; LI, Fuhai; LIU, Min; LIAO, Hanlin ${ }^{\mathrm{c}}$}

\footnotetext{
${ }^{a}$ MSMP Laboratory, EA-7350, Arts et Metiers ParisTech, Aix en Provence, France

${ }^{\mathrm{b}}$ Guangdong Institute of New Materials, 363 Changxing Road, Gunangzhou, 510651, PR China

' ICB UMR 6303, CNRS, Univ. Bourgogne Franche-Comté, UTBM, F-90010 Belfort, France
}

\section{Introduction}

\subsection{Background}

Additive manufacturing (AM), a layer by layer material processing, is considered as an efficient way to produce complex-shaped components in a "design to manufacturing" objective. Selective laser melting (SLM), a laser-sourced \& powder-bed AM, presents high processing accuracy and design freedom due to the thin layer thickness and small laser beam diameter [1,2]. In this process, 3D CAD model is created and sliced into a finite number of layers, each corresponding to a layer of powder during the building procedure. The desired 3D component is manufactured by the repetition, layer by layer, of selective sintering of the powder bed by laser beam. Recently, Fe-based [3,4], Al-based [5,6], Ni-based [7] and Ti-based [8] alloys based component in extremely sophisticated morphology, such as lattice structure, have been successfully manufactured by SLM process with desired properties and various applications.

Metal matrix composite (MMC) is one system which benefits from the advantages of both reinforcements and matrix materials. Hence, the addition of high hardness ceramic particles ( $\mathrm{SiC}, \mathrm{TiC}, \mathrm{WC}$ and $\mathrm{BN}_{4}$ etc.) into conventional alloys could significantly improve the wear/corrosion resistance of matrix material (e.g. $\mathrm{Cu}, \mathrm{Al}$ and $\mathrm{Fe}$ etc.) without losing much ductility $[9,10]$. Up to date, MMCs were successfully employed in various industrial fields, such as medical (Ti-matrix) [10], aerospace
(Ni-matrix) [11], aeronautics (ceramic-matrix) [12] and civil engineering (Fe matrix) [13,14]. Those applications are usually manufactured by conventional processes, like casting [15] and powder metallurgy [16].

\subsection{Objective of this work}

The material synthesis possibility of SLM should also be investigated and discussed, for example, from high cooling rate to ultrafine/metastable/amorphous structure [17]. Furthermore, the layer by layer production procedure is irreplaceable in the elaboration of novel composite materials with large density difference between reinforcement and matrix, which cannot be easily prepared by conventional casting. In the past years, SLM has been considered to produce various MMCs, from light-weighted [18] to heavy-weighted [19] matrix, from crystalline [20] to amorphous [21] reinforcements. Among them, Febased alloys and composites, especial steels, draw extensive attention because of their wide range of applications and well-investigated scientific background, their low cost and high laser absorptivity [22-29]. Maraging steel is widely used in molds industry thanks to their high mechanical strength and thermal stability $[30,31]$. Nowadays, with the growing requirement on morphologic complexity of mold component, such as conformal cooling channels, additive manufacturing presents great potential in industrial application instead of conventional casting [32]. But the mechanical strength and wear resistance of the AM steel 
Table 1

Chemical composition of $18 \mathrm{Ni}-300$ maraging steel powder (wt.\%).

\begin{tabular}{|c|c|c|c|c|c|c|c|c|c|c|}
\hline Element & $\mathrm{Fe}$ & $\mathrm{Ni}$ & Co & Mo & $\mathrm{Ti}$ & $\mathrm{Al}$ & $\mathrm{C}$ & $\mathrm{Cr}, \mathrm{Cu}$ & $\mathrm{Si}, \mathrm{Mn}$ & $\mathrm{S}, \mathrm{P}$ \\
\hline wt.\% & Bal & $17-19$ & $8.5-9.5$ & $4.5-5.2$ & $0.6-0.8$ & $0.05-0.15$ & $\leq 0.03$ & $\leq 0.5$ & $\leq 0.1$ & $\leq 0.1$ \\
\hline
\end{tabular}

molds need to be improved for a longer lifetime, which is usually obtained by thermal and finishing treatments [33]. Tungsten carbide (WC) presents high strength and hardness, low friction coefficient and high melting temperature, which improve the wear resistance under high friction and temperatures conditions, to which the molds are subjected during use, without strength reduction. As mentioned above, with the limitation of great density difference between WC and maraging steel, it is very difficult to obtain a mold component with a homogenous distribution of WC by using conventional casting [34]. Therefore, in this work, SLM was used to in-situ fabricate the WC reinforced maraging steel from powder mixture with several WC contents. Additionally, the wear resistance of SLM processed maraging steel and its composite was determined by our work [35], which indicates the wear resistance was significantly improved by adding WC into maraging steel.

\section{Experimental details}

WC (3-5 $\mu \mathrm{m}$, Guangdong institute of new material, China) and Maraging steel $(20-66 \mu \mathrm{m}$, EOS, Germany) powders, with chemical composition reported in Table 1, were used in this work. The feedstock powder mixtures were obtained by using a mechanical tumbling mixer for $60 \mathrm{~min}$ with several weight proportions of WC/maraging steel: 5/ 95; 10/90; and 15/85. An example of the powder mixture morphology with $5 \%$ WC is shown in Fig. 1(a). It indicates that the WC reinforcement presents a uniform distribution in powder mixture. Details about the maraging steel $18 \mathrm{Ni}-300$ (MS1) powder can be found in the material data sheet supplied by EOS [32]. Commercially available SLM machine EOS M 290 (EOS GmbH, Germany) equipped with a $400 \mathrm{~W}$ Nd-YAG fiber laser beam was used for cubic $\left(8 * 8 * 5 \mathrm{~mm}^{3}\right)$ samples without support structure and tensile samples (see in Fig. 1(b)). A constant laser power of $275 \mathrm{~W}$ and a scanning speed of $1360 \mathrm{~mm} / \mathrm{s}$ were used. The
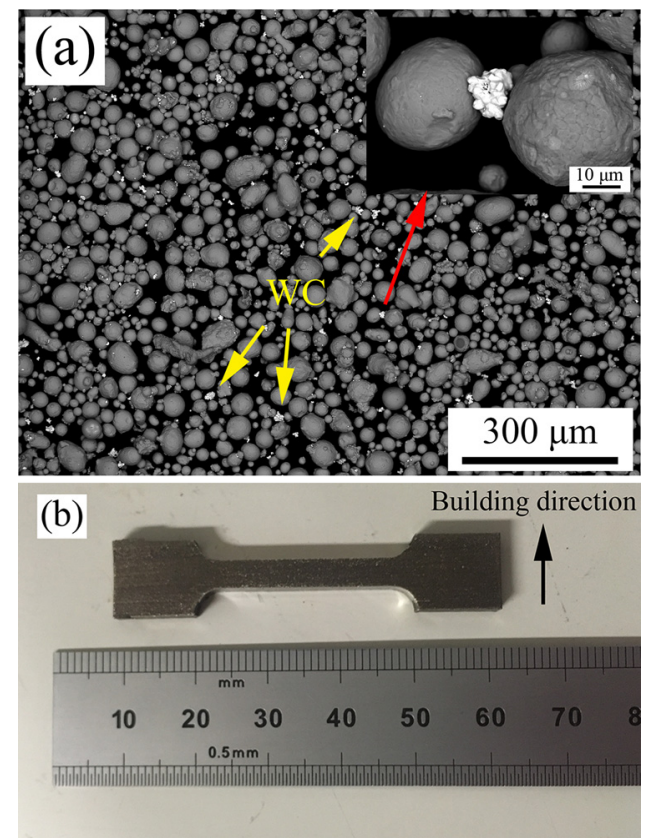

Fig. 1. (a) SEM images of powder mixture of WC and maraging steel and (b) asfabricated tensile sample. layer thickness was fixed at $50 \mu \mathrm{m}$ during the manufacturing process under $\mathrm{N}_{2}$ atmosphere.

X-ray diffraction (XRD) on a Siemens XRD system with Co Ka radiation $(\lambda=1.78897 \AA)$ operated at $35 \mathrm{kV}$ and $40 \mathrm{~mA}$, was used to characterize the phase composition in different WC contents. The microstructure was studied by a Scanning Electron Microscope (SEM, JEOL, Japan) equipped with X-ray energy dispersive spectroscopy (EDS). The interfacial microstructure was characterized by Transmission Electron Microscopy (TEM, JEM2100F, JEOL, Japan). Additionally, before characterization of TEM, the test sample was prepared by Focused Ion Beam (FIB, 450S, FEI, Japan) milling with low induced stress and material. A $100 \mathrm{kN}$ INSTRON tensile test machine equipped with an extensometer were employed to determine the tensile properties of SLM processed maraging steel and its composites. The tensile rate was set as $10^{-4} / \mathrm{s}$. Observations of the specimens' fracture surfaces were conducted by SEM.

\section{Results and discussions}

\subsection{Roughness}

The roughness of upper surface of SLM processed samples in two directions along $(\mathrm{X})$ and cross $(\mathrm{Y})$ laser trace were measured and calculated with Ra (see in Fig. 2(a)):

$\mathrm{R}_{\mathrm{a}}=\frac{1}{\mathrm{n}} \sum_{\mathrm{i}=1}^{\mathrm{n}}\left|\mathrm{y}_{\mathrm{i}}\right|$

On the one hand, the average value of roughness of SLM processed maraging steel decreases from about of $8 \mu \mathrm{m}$ to $4 \mu \mathrm{m}$ when the WC content increases from $0 \%$ to $15 \%$ and the minimum Ra value is about $3 \mu \mathrm{m}$ in the samples with $10 \%$ WC. On the other hand, the difference between the roughness in $\mathrm{X}$ and $\mathrm{Y}$ directions is gradually eliminated, that is to say, the surface morphology changes from anisotropic to homogenous after adding the WC reinforcement. On the basis of the report of Li et al. [36], for the high relative density case, the overlapped region plays the key factor on roughness of SLM processed part. In this study, the thermal conductivity of WC $(110 \mathrm{~W} /(\mathrm{m} \mathrm{K}))$ is higher than that of maraging steel $(15 \mathrm{~W} /(\mathrm{m} \mathrm{K}))$ [32]. According to the rule of mixture [37], the thermal conductivity with several WC contents are shown in Table 2. It can be seen that the thermal conductivity was significant improved from 15 to $23 \mathrm{~W} /(\mathrm{m} \mathrm{K})$ after adding $15 \% \mathrm{WC}$. Thus the composite material both in solid and powder state, presents higher thermal conductivity than that of pure maraging steel. It leads to a larger melting pool with a higher temperature. Therefore, the overlapped region of composite material can be more easily melted during SLM process than the pure maraging steel resulting on an increment in surface quality. Beside of the thermal properties, in general, the defect appears at the interfacial region between reinforcement and matrix materials. In this work, the interfacial structure were investigated by FIB and TEM tests (Fig. 4), which indicates a perfect dense interfacial structure. This results can be attributed to high diffusion coefficient between $\mathrm{W}$ and $\mathrm{Ti}$ at high temperature, leading to dense metallurgical bonding. Therefore, the laser-induced defect was reduced.

Furthermore, Fig. 2(b and c) show the surface morphologies of SLM processed samples without and with WC. It can be observed that, as the WC is added, the laser traces (indicated by red line in Figures) are eliminated. Instead of that, a cellular pattern appears on the surface. According to the elemental analysis (EDS), the dark region between two laser traces corresponds to a titanium rich region. The SLM processed 

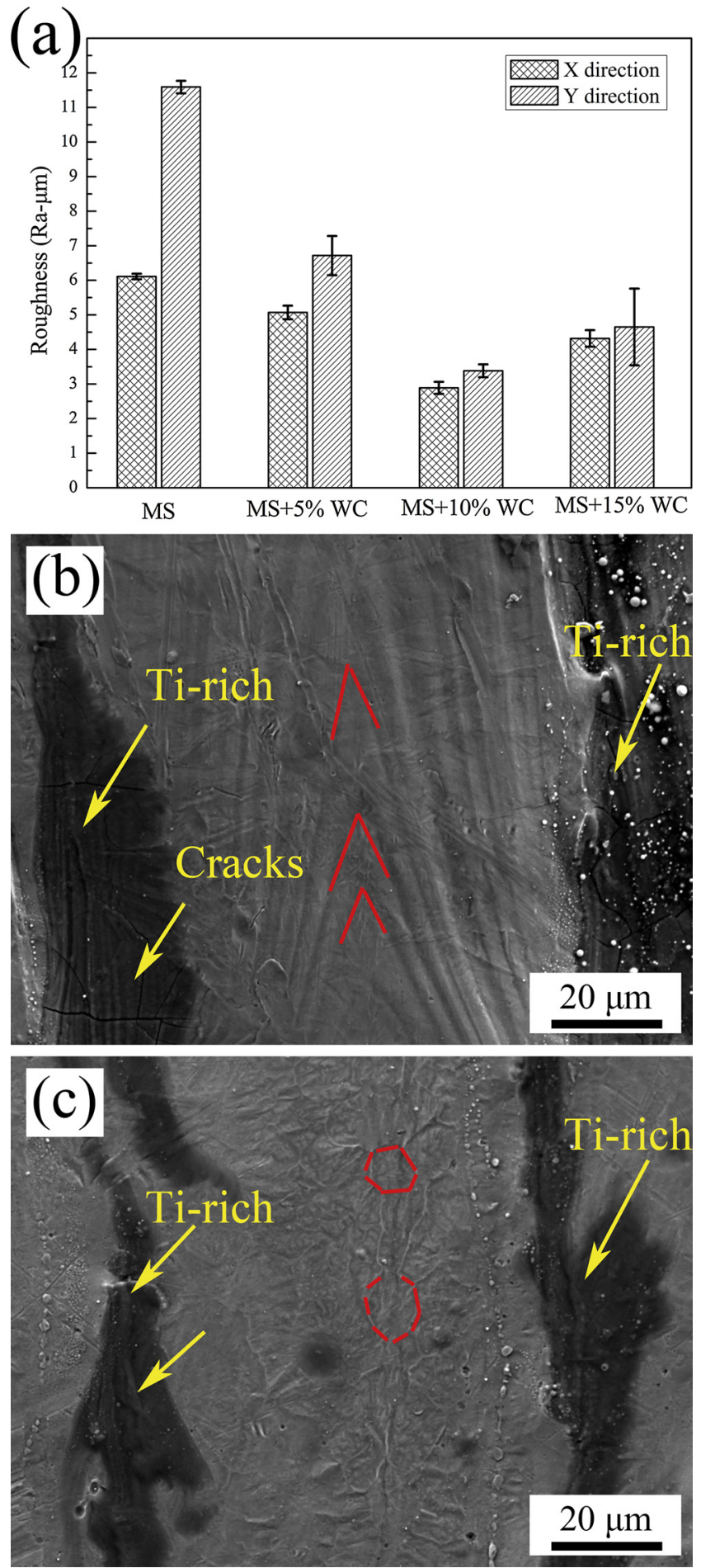

Fig. 2. (a) Roughness and (b and c) surface morphologies of as-fabricated maraging steel and its composites (15\%WC).

Table 2

Thermal conductivity of SLM processed samples (Rule of mixture).

\begin{tabular}{lll}
\hline Samples (wt.\%) & WC content (vol.\%) & Thermal conductivity (W/ (m K)) \\
\hline MS & 0 & 15 \\
MS + 5\%WC & 2.6 & 17.5 \\
MS + 10\%WC & 5.5 & 20.2 \\
MS + 15\%WC & 8.4 & 23.0 \\
\hline
\end{tabular}

composite shows lower proportion of Ti-rich region than pure maraging steel. On the other hand, the crack on surface disappears after adding the WC reinforcement. According to XRD analysis (Fig. 5), a phase transition from $b c c$ to $f c c$ could be observed. In general, because of the effect of glide plane, the $f c c$ phase presents higher ductility than that of $b c c$ phase. Thus, the high ductile $f c c$ phase (composite sample) presents less crack in SLM processed sample.

\subsection{Microstructure}

The OM images of SLM processed sample with several WC contents $(0,5,10$ and $15 \%$ in powder mixtures) are shown in Fig. 3. Some small spherical pores appear on the SLM processed maraging steel (Fig. 3(a)) and composite samples (Fig. 3(b, c and d)), which can be attributed to intrinsic properties of laser melting process [38]. The gas is trapped into the molten pool and small spherical porosities are formed. The WC particles could be observed in the composite samples with a relative homogenous distribution (see in Fig. 3(b-d)). According to the image analysis results, the WC contents of as-fabricated samples, about $3 \%$, $4 \%$ and $5 \%$, which are lower than that of powder mixtures $5 \%, 10 \%$ and $15 \%$. During SLM process, metallic powder is melted by the high energy density laser, and then rapidly solidified. Therefore, the reasons for the decrement of WC content in as-fabricated samples could be listed:

(1) WC was fully or partially melted by laser and merged with the matrix in a solid solution, which can also be observed at the work of SLM processed WC in Ref. [39,40].

(2) The diffusion between WC and maraging steel occurred in molten pool during SLM process.

The SEM images of FIB prepared cross-section of interfacial region between WC reinforcement and maraging steel are shown in Fig. 4(a and b). Interfacial region presents a dense microstructure without clear surface separation. In general, the grain size of maraging steel in region far from WC particles is larger than that of region near WC particles. Moreover, the morphology of grains changes from columnar to equiaxed as the distance to WC decreases (Fig. 4(b)). One possible reason is the high thermal conductivity of WC (mentioned in 3.1 Section) leading to a high cooling rate of the molten pool, which causes a refinement of the microstructure. The elemental distribution analysis was determined by TEM-EDS (see in Fig. 4(c-g)), which indicates that a diffusion behavior appears between WC particles and maraging steel. Moreover, the diffusion rate depends on the element, for example $\mathrm{Fe}$, $\mathrm{Co}$ and Ni present lower diffusion with $\mathrm{W}$ than Ti. These elemental diffusions between matrix and reinforcement permit to form a strong metallurgical bonding. From Fig. 4(b and g), it can also be observed that $\mathrm{W}$ element mainly appears at the grains boundary of maraging steel. Indeed, the grain boundary acts as an important diffusion channel during the SLM process, which causes the micro-segregation.

\subsection{Phases analysis}

Fig. 5 presents the XRD patterns of SLM processed maraging steel and composites. As shown in Fig. 5(a), in the case of maraging steel, only bbc ( $\alpha-\mathrm{Fe})$ phase could be observed on the XRD pattern, which well corresponds to the works of EOS Company and Kempen et al. $[32,41]$. The addition of WC presents significant influence on the phase composition. Firstly, the main phase changed from bbc $\alpha$ in pure maraging steel to fcc $\gamma$ with addition of WC regardless of the proportion (from 5\% to 15\%). The local view is shown in Fig. 5(b). The appearance of $\gamma$-Fe may be attributed to numerous reason, such as chemical composition change, high cooling rate and residual stress. For example, according to the report of Cacciamani et al. [42], due to the low diffusion rate of nickel in $\alpha-\mathrm{Fe}$, the transformation of $\alpha$ to $\gamma$ appears in the cases of rapid solidification. Unfortunately, the reasons for this 

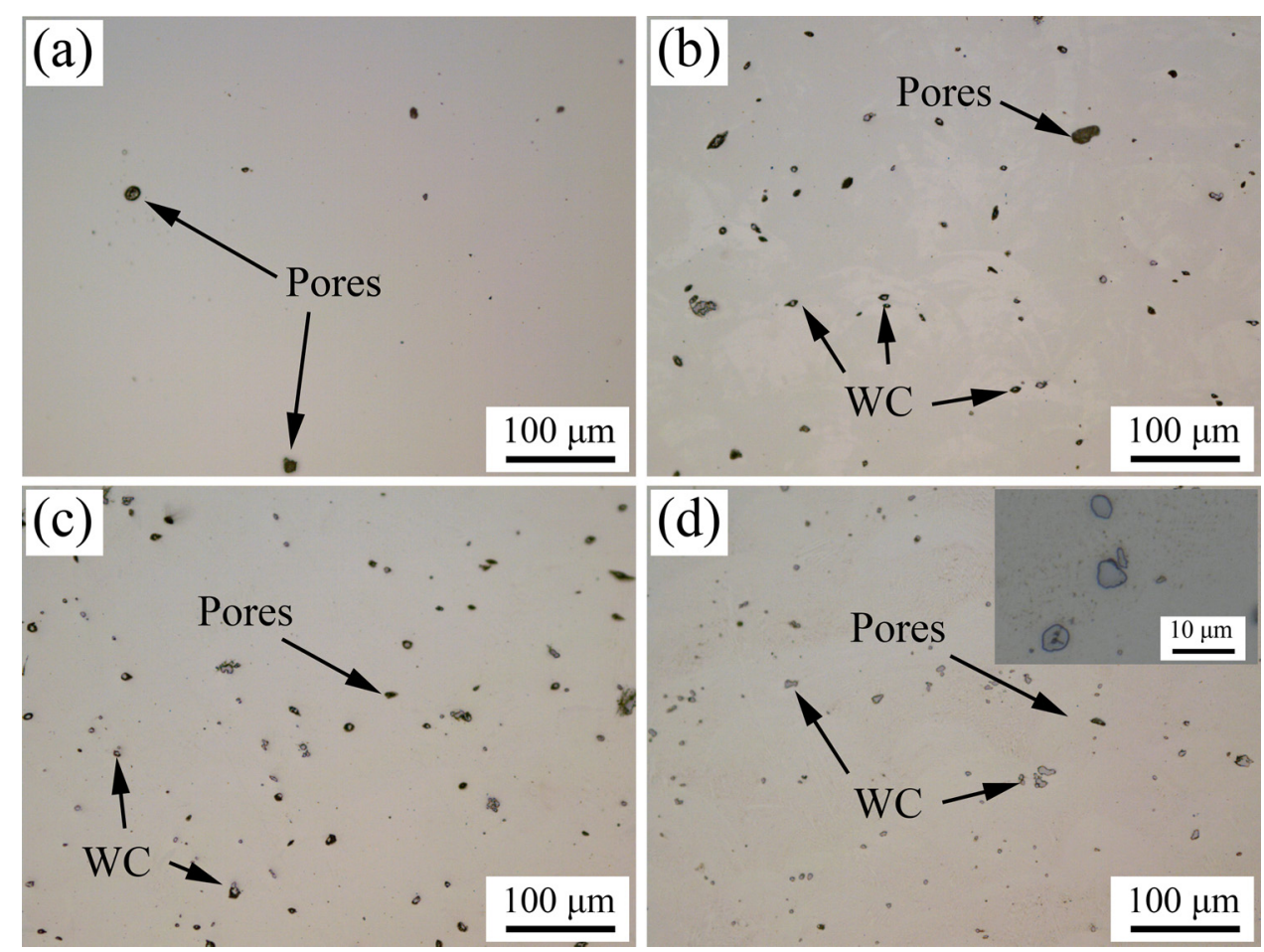

Fig. 3. OM images of SLM processed (a) maraging steel and its composite with several WC content (b) $5 \%$, (c) $10 \%$ and (d) $15 \%$.

transition are not clear. One possible reason for this work may be that adding the highly thermal conductive WC particles into maraging steel could improve the thermal conductivity (cooling rate) of molten pool during SLM process. Furthermore, the large-sized W element holds back the phase transition from high temperature fcc $\gamma$ phase to low temperature bcc $\alpha$ phase. Thus, $\gamma$ (Fe, Ni) appears on the SLM processed composite sample instead of bcc $\alpha$ phase in maraging steel. Additionally, due to the nonequilibrium solidification properties of SLM process, the $\gamma(\mathrm{Fe}, \mathrm{Ni})$ appears in a scope of XRD parttern, which can be affected by numerous factors, such as chemical composition, residual stress etc. The diffusion of elements at the interface matrix particles was also reported by Rong et al. [43] in the case of SLM processed WC/Inconel 718 composite. Moreover, due to the high melting temperature of WC and the diffusion behavior, the large sized particles present $\mathrm{WC}_{1-\mathrm{x}}$ phase.

\subsection{Tensile tests}

The tensile curves, which is repeated by 3 times, of SLM processed
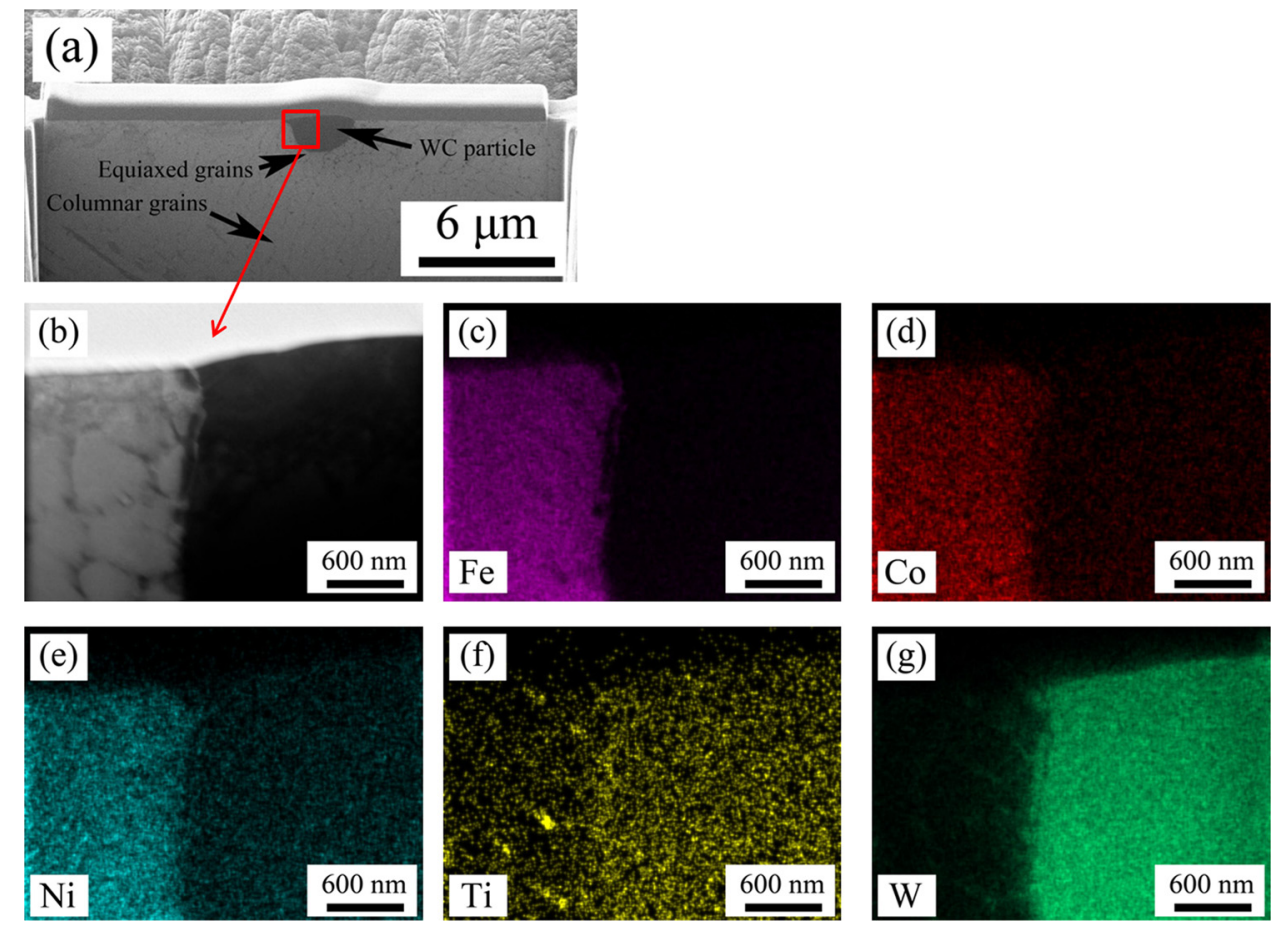

Fig. 4. TEM images of SLMed 10\% WC/maraging steel composite (a) FIBed sample (b) interface with elemental distribution (c) Fe, (d) Co, (e) Ni, (f) Ti and (g) W. 


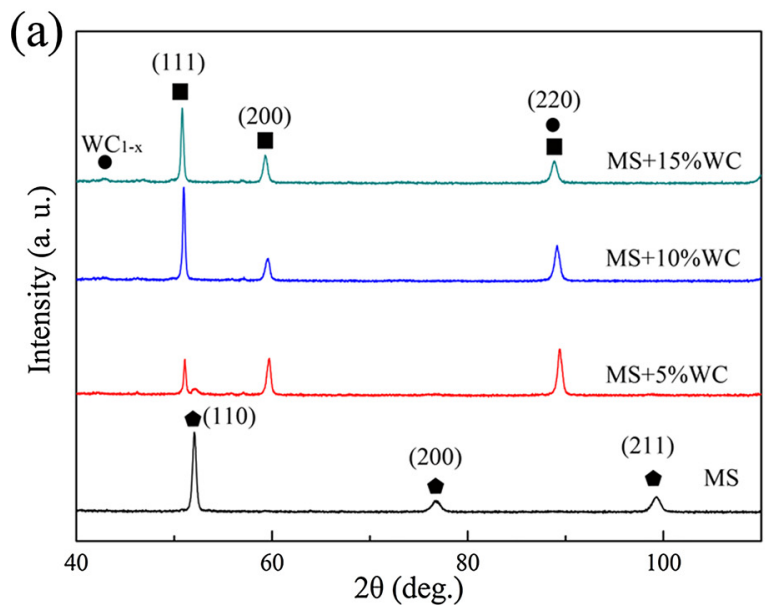

(b)

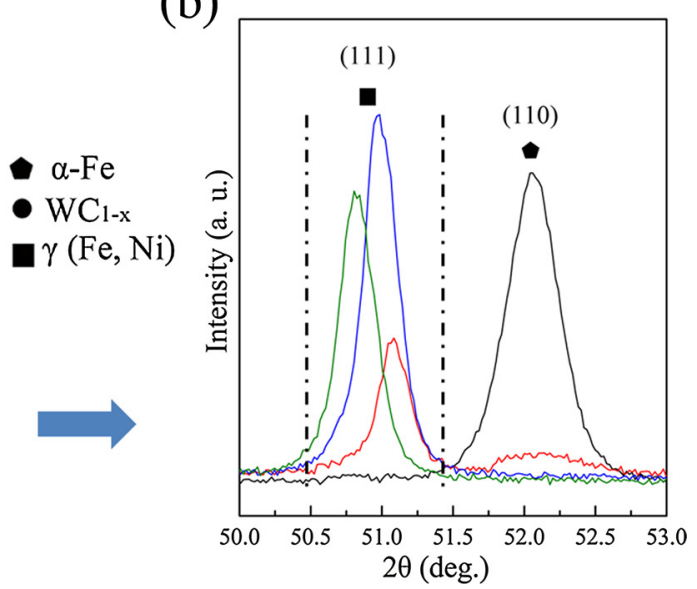

Fig. 5. (a) over and (b) local views of XRD patterns of SLM processed maraging steel and its composites, 5, 10 and $15 \%$ WC.

samples with or without WC reinforcement are shown in Fig. 6. As it can be seen the addition of 5\% WC changes the mechanical response of the maraging steel. In the elastic deformation domain the Young's modulus remains fairly constant. Yet the elastic domain is reduced by the addition of WC, indeed in the pure maraging steel the yield strain is about $1.15 \%$ and the Yield stress is about $1060 \mathrm{MPa}$ while in the 5\% WC they are respectively about $0.56 \%$ and $561 \mathrm{MPa}$. However after a small plastic deformation-like plateau, the 5\% WC displays a strong consolidation with the increase of the stress with further strain. The 5\% WC maraging steel shows a higher UTS and a higher homogeneous deformation since no necking was observed up to failure at about $12 \%$ ( $\pm 2 \%$ ). It can be observed that this composite showed a tensile curve in three parts, elastic deformation, plastic plateau quite similar to that of pure maraging steel (but at lower stress) and a third part showing a lower apparent modulus and a very rugged evolution. These repeated accidents could be attributed to initiation of micro-cracks at the surface and at the fracture of WC particles in the matrix as it will be discussed later considering fractographs. In the $10 \%$ WC composite the third part of the curve was not observed, probably due to a weakening associated with a higher WC particles content.

Moreover, during the tensile test, an important necking phenomenon appears on the SLM processed maraging steel, that was not observed in its composites. It can be attributed to the poor surface quality of the pure maraging steel in which the defects inherited from SLM

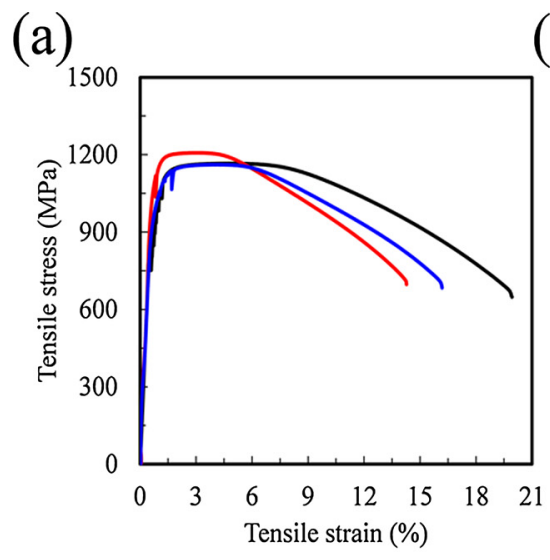

(b)
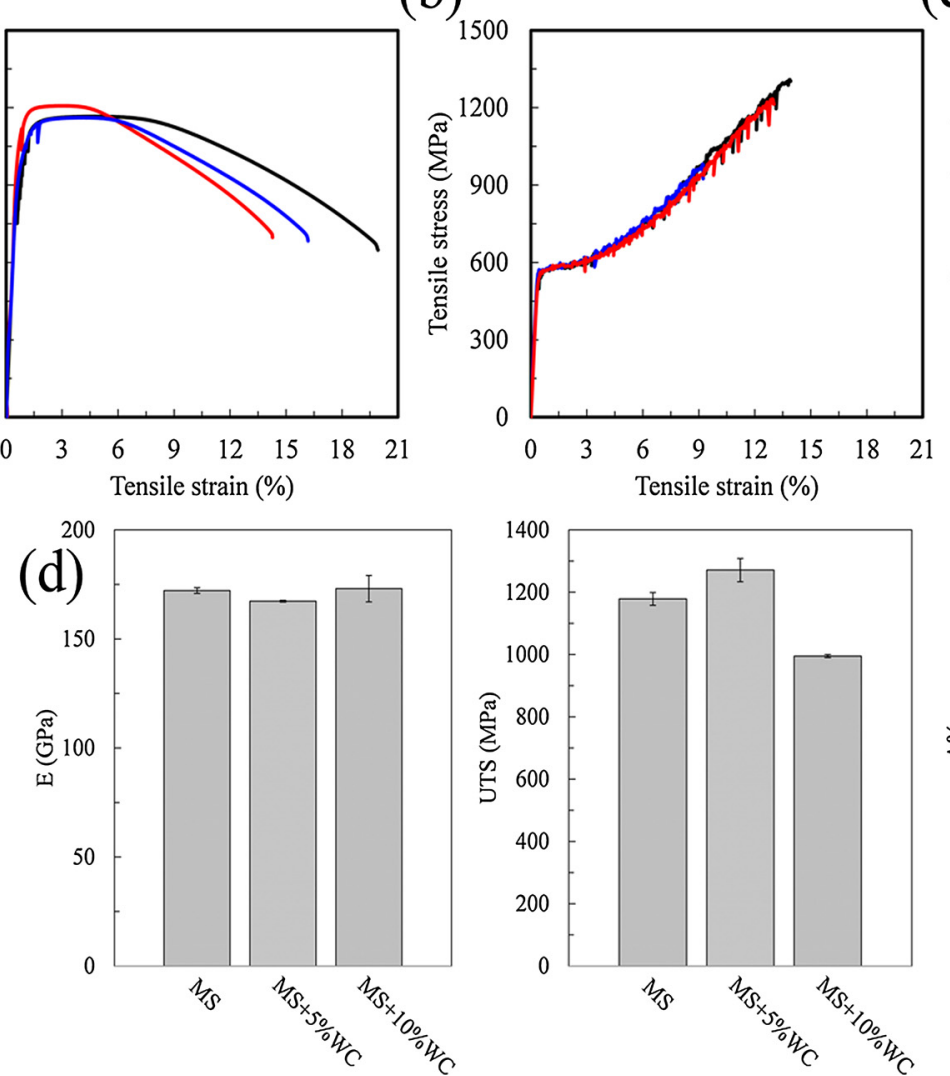

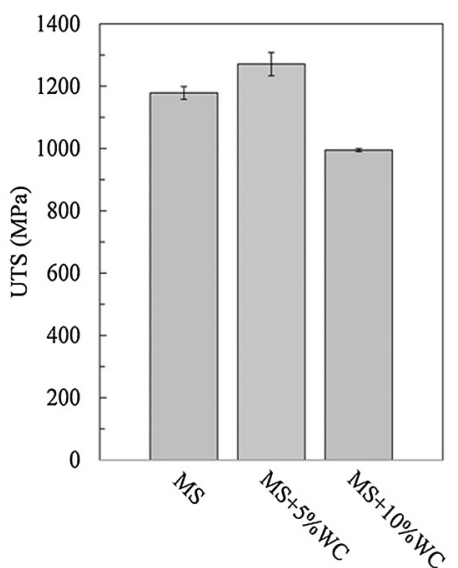

(c)
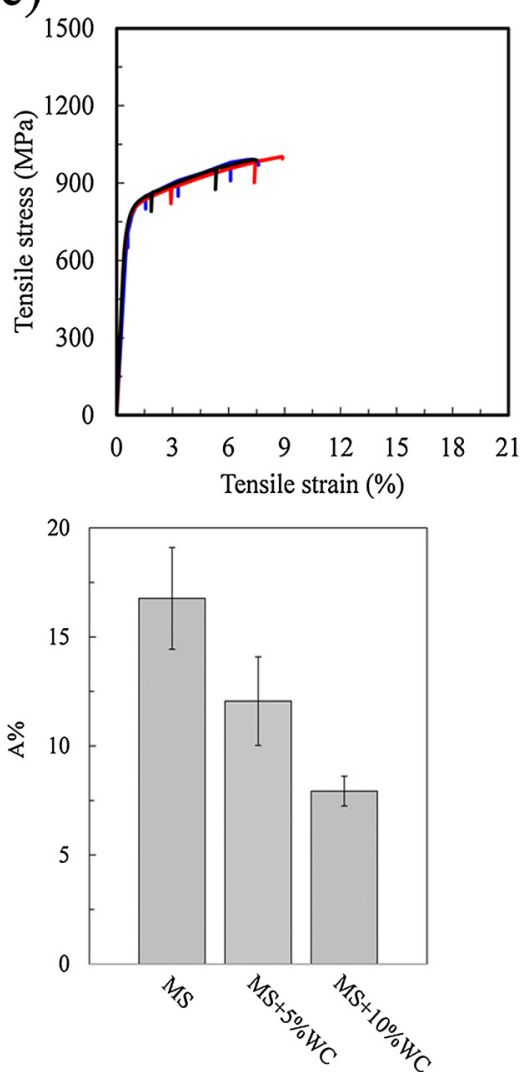

Fig. 6. Tensile curves of SLM processed (a) maraging steel and its composites with several WC contents (b) 5\%, (c) 10\% and (d) the mechanical properties of SLM processed maraging steel and its composites. Young's modulus (E), Ultimate tensile strength (UTS), and Strain at failure (A\%). 


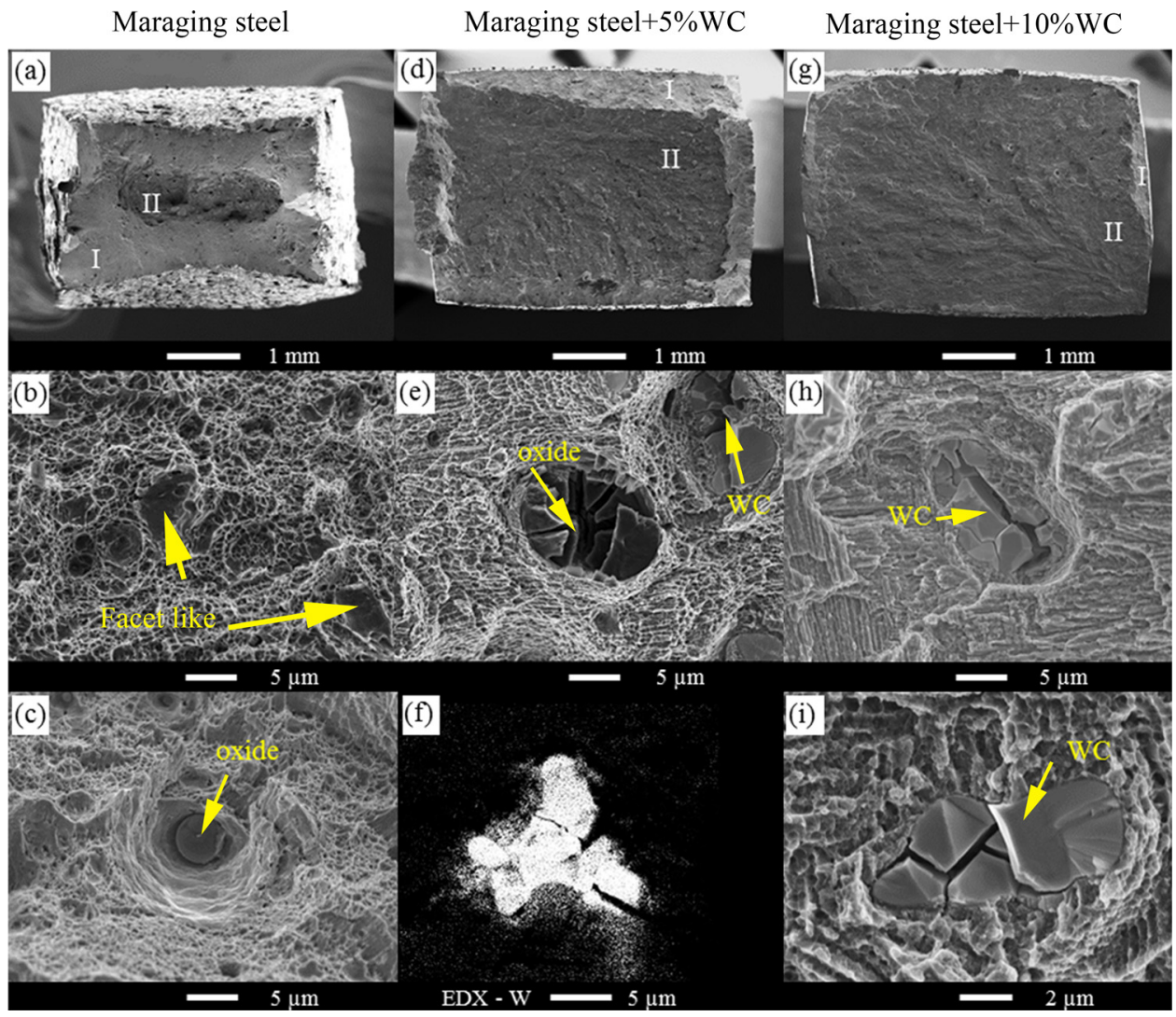

Fig. 7. SEM observation of fracture surface of SLM processed maraging steel (a, b, c) and its composite with several WC content $5 \%$ (d, e f) and 10\% (g, i, h) (W composition : chemical bounding with the matrix along the grain boundaries).

process initiate the necking. The homogeneous deformation of pure maraging steel was fairly low, about 7\%, and then the necking led to an inhomogeneous deformation with the drop of the stress. Meanwhile, the three tensile curves of the composites were entirely overlapped, which is not the case of maraging steel. That is to say that the repeatability of SLM processed composites is better than that of maraging steel. With the addition of WC reinforcement, the surface roughness and surface cracks were significantly decreased. So, the effect of as-fabricated cracks on tensile properties could be reduced, leading to higher process repeatability.

Fig. 7 shows the fracture surface of SLM processed maraging steel and composite with $5 \%$ and $10 \%$ WC. The fracture section area of maraging steel is larger than that of composite materials, which confirms the necking effect during the tensile test and the high ductility of maraging steel (see in Fig. $7(\mathrm{a}-\mathrm{c})$ ). Additionally, the fracture surface can be divided into 2 different regions: (I) the contour and (II) center. The high magnification images of crack propagation and pull out regions in maraging steel are shown in Fig. 7(b-c). As shown in Fig. 7(b), the crack propagation region presents a ductile fracture with dimples. Moreover, some facet-like fracture surfaces could be observed in MS sample (Fig. 7(b)), which is always appears on the fracture surface of SLM processed sample and investigated by Suryawanshi et al. [44]. In addition to dimples, some particles and porosities can be observed in the maraging steel sample as it can be seen in Fig. 7(c, e). These particles have been characterized by EDS and correspond to titanium and aluminum oxides. These observations are confirmed by the work of Thijs et al. [45], the authors reported $\mathrm{Al}_{2} \mathrm{O}_{3}$ and $\mathrm{Ti}_{3} \mathrm{O}_{5}$ oxides inclusions due to the oxide layer that forms on each layer during the SLM process, the deposition of the next layer breaks the oxide layer, leading to oxides inclusions trapped into the material. The oxides inclusions create porosity initiations at the interface with the matrix that cause the tunnellike holes with inclusions at the bottom. In SLM processed composites, besides oxides particles, fragmentized WC particles appear on the fracture surface. As it can be seen in Fig. 7(e) in the center of the figure a broken oxide inclusion is clearly identified and a WC particle is observable in the upper right. WC particles are also observable by BSE in Fig. $7(\mathrm{~h})$, and a zoom on a particle in the $10 \%$ WC composite is visible in Fig. 7(i).

In both cases, the fractures originate from the crack propagation region, which manifests a high ductility. Then in maraging steel, the defects, such as porosities and oxides inclusions, act as new crack source. Thus, numerous porosities and oxides inclusions can be observed in the pull-out region. Similar results and mechanisms were reported by a previous work of the authors on the SLM processed Al12Si alloys [46]. The new crack sources in SLM processed composites are the WC particles, due to their intrinsic fragile mechanical properties as it can be seen in Fig. 7(e, h, i). Furthermore, that shows the strong chemical bounding between WC particles and the steel matrix illustrated by the EDS analysis Fig. 7(f) which highlights the diffusion of W in the grain boundaries of the matrix. The homogenous WC distribution in maraging steel leads to a plane fracture surface (Fig. $7(\mathrm{~d}, \mathrm{~g})$ ). Furthermore, given to the high tensile strength of WC, the rupture of WC particles leads to small declines of tensile stress that explain the irregularities observed in the curves in Fig. 6(b). Therefore, the tensile curve of SLM processed composite illustrates three steps: (1) elastic deformation; (2) plastic deformation without WC fracture and (3) plastic deformation with WC fracture.

\section{Conclusion}

In summary, the WC reinforced $18 \mathrm{Ni}-300$ maraging steel composite was in-situ manufactured by selective laser melting process with high relative density. The effects of WC addition on tensile properties were investigated. With the addition of WC reinforcement: 
(1) The surface quality was improved, showed by the value of Ra and a more homogeneous morphology.

(2) The phase of SLM processed maraging steel matrix was affected with a transformation from $\alpha$-Fe to $\gamma(\mathrm{Fe}, \mathrm{Ni})$.

(3) The interfacial analysis indicated that element-dependent diffusion behavior takes place between WC particle and maraging steel matrix during SLM process.

(4) In terms of tensile properties, the SLM processed composite with 5\% WC presents a maximum UTS near $1300 \mathrm{MPa}$. No clear influence of WC particles on the Young's modulus was observed. Moreover, it was observed that the repeatability (stability of mechanical properties) of SLM processed composite is higher than that of SLM processed maraging steel, which can be attributed to their low surface roughness.

\section{Acknowledgements}

One of the authors, N. KANG, is grateful for the financial support provided by the China Scholarship Council (Grant No. 201206290187) and Marie CurieFP7-IPACT-268696(EU). This work is also supported by foundations (Grant No.): 2014B050502008, 2016201604030028, 2016B070701020, 2016G1FC0004. The authors are also grateful for the help of Mr. Jianbo XU.

\section{References}

[1] W.E. Frazier, Metal additive manufacturing: a review, J. Mater. Eng. Perform. 23 (2014) 1917-1928.

[2] M. Tang, P.C. Pistorius, J.L. Beuth, Prediction of lack-of-fusion porosity for powder bed fusion, Addit. Manuf. 14 (2017) 39-48.

[3] B. AlMangour, M.-S. Baek, D. Grzesiak, K.-A. Lee, Strengthening of stainless steel by titanium carbide addition and grain refinement during selective laser melting, Mat Sci. Eng. A Struct. 712 (2018) 812-818.

[4] B. AlMangour, D. Grzesiak, T. Borkar, J.-M. Yang, Densification behavior, microstructural evolution, and mechanical properties of TiC/316L stainless steel nanocomposites fabricated by selective laser melting, Mater. Des. 138 (2018) 119-128.

[5] P. Wang, H.C. Li, K.G. Prashanth, J. Eckert, S. Scudino, Selective laser melting of Al$\mathrm{Zn}-\mathrm{Mg}$-Cu: heat treatment, microstructure and mechanical properties, J. Alloys Compd. 707 (2017) 287-290.

[6] N. Kang, P. Coddet, H.L. Liao, T. Baur, C. Coddet, Wear behavior and microstructure of hypereutectic Al-Si alloys prepared by selective laser melting, Appl. Surf. Sci. 378 (2016) 142-149.

[7] M.J. Xia, D.D. Gu, Dai D.H. Yu GQ, H.Y. Chen, Q.M. Shi, Porosity evolution and its thermodynamic mechanism of randomly packed powder-bed during selective laser melting of inconel 718 alloy, Int. J. Mach. Tool Manuf. 116 (2017) 96-106.

[8] Z. Chen, X. Wu, D. Tomus, C.H.J. Davies, Surface roughness of selective laser melted Ti-6Al-4V alloy components, Addit. Manuf. 21 (2018) 91-103.

[9] B. AlMangour, D. Grzesiak, J.-M. Yang, Selective laser melting of TiB2/316L stainless steel composites: the roles of powder preparation and hot isostatic pressing post-treatment, Powder Technol. 309 (2017) 37-48.

[10] N. Kang, P. Coddet, Q. Liu, H.L. Liao, C. Coddet, In-situ TiB/near a Ti matrix composites manufactured by selective laser melting, Addit. Manuf. 11 (2016).

[11] X. Wu, P. Wollgramm, C. Somsen, A. Dlouhy, A. Kostka, G. Eggeler, Double minimum creep of single crystal Ni-base superalloys, Acta Mater. 112 (2016) 242-260.

[12] X.M. Duan, Z.H. Yang, L. Chen, Z. Tian, D.L. Cai, Y.J. Wang, D.C. Jia, Y. Zhou, Review on the properties of hexagonal boron nitride matrix composite ceramics, J. Eur. Ceram. Soc. 36 (2016) 3725-3737.

[13] D. Gu, J. Ma, H. Chen, K. Lin, L. Xi, Laser additive manufactured WC reinforced Febased composites with gradient reinforcement/matrix interface and enhanced performance, Compos. Struct. 192 (2018) 387-396.

[14] B. AlMangour, D. Grzesiak, J.-M. Yang, Nanocrystalline TiC-reinforced H13 steel matrix nanocomposites fabricated by selective laser melting, Mater. Des. 96 (2016) 150-161.

[15] S. Singh, D. Gupta, V. Jain, Novel microwave composite casting process: theory, feasibility and characterization, Mater. Des. 111 (2016) 51-59.

[16] S.S. Li, Y.S. Su, Q.B. Ouyang, D. Zhang, In-situ carbon nanotube-covered silicon carbide particle reinforced aluminum matrix composites fabricated by powder metallurgy, Mater. Lett. 167 (2016) 118-121.

[17] S. Pauly, L. Löber, R. Petters, M. Stoica, S. Scudino, U. Kühn, J. Eckert, Processing metallic glasses by selective laser melting, Mater. Today 16 (2013) 37-41.

[18] D.D. Gu, H.Q. Wang, D.H. Dai, P.P. Yuan, W. Meiners, R. Poprawe, Rapid fabrication of Al-based bulk-form nanocomposites with novel reinforcement and enhanced performance by selective laser melting, Scr. Mater. 96 (2015) 25-28.

[19] T. Rong, D.D. Gu, Formation of novel graded interface and its function on mechanical properties of $\mathrm{WC}_{1-\mathrm{x}}$ reinforced inconel 718 composites processed by selective laser melting, J. Alloys Compd. 680 (2016) 333-342.

[20] N. Kang, Y. Fu, P. Coddet, B. Guelorget, H. Liao, C. Coddet, On the microstructure, hardness and wear behavior of $\mathrm{Al}-\mathrm{Fe}-\mathrm{Cr}$ quasicrystal reinforced $\mathrm{Al}$ matrix composite prepared by selective laser melting, Mater. Des. 132 (2017) 105-111.

[21] X.P. Li, M.P. Roberts, S. O'Keeffe, T.B. Sercombe, Selective laser melting of Zr-based bulk metallic glasses: processing, microstructure and mechanical properties, Mater. Des. 112 (2016) 217-226.

[22] B. AlMangour, D. Grzesiak, M. Jenn, Selective laser melting of TiC reinforced 316I stainless steel matrix nanocomposites: influence of starting TiC particle size and volume content, Mater. Des. 104 (2016) 141-151.

[23] B. AlMangour, D. Grzesiak, J.-M. Yang, Rapid fabrication of bulk-form TiB2/316L stainless steel nanocomposites with novel reinforcement architecture and improved performance by selective laser melting, J. Alloy Compd. 680 (2016) 480-493.

[24] B. AlMangour, D. Grzesiak, J.-M. Yang, In situ formation of TiC-particle-reinforced stainless steel matrix nanocomposites during ball milling: feedstock powder preparation for selective laser melting at various energy densities, Powder Technol. 326 (2018) 467-478.

[25] B. AlMangour, D. Grzesiak, J.-M. Yang, Scanning strategies for texture and anisotropy tailoring during selective laser melting of TiC/316L stainless steel nanocomposites, J. Alloy Compd. 728 (2017) 424-435.

[26] B. AlMangour, D. Grzesiak, J.-M. Yang, In-situ formation of novel TiC-particle-reinforced 316L stainless steel bulk-form composites by selective laser melting, J. Alloy Compd. 706 (2017) 409-418.

[27] B. AlMangour, D. Grzesiak, J.-M. Yang, Selective laser melting of TiB2/H13 steel nanocomposites: influence of hot isostatic pressing post-treatment, J. Mater. Process Tech. 244 (2017) 344-353.

[28] B. AlMangour, F. Yu, J.-M. Yang, D. Grzesiak, Selective laser melting of TiC/H13 steel bulk-form nanocomposites with variations in processing parameters, MRS Commun. 7 (2017) 84-89.

[29] F. Deirmina, B. AlMangour, D. Grzesiak, M. Pellizzari, H13-partially stabilized zirconia nanocomposites fabricated by high-energy mechanical milling and selective laser melting, Mater. Des. 146 (2018) 286-297.

[30] W. Sha, Z. Guo, Maraging Steels- Modelling of Microstructure, Properties and Applications, Woodhead Publishing Ltd., Cambridge, UK, 2009.

[31] F. Zhu, Y.F. Yin, R.G. Faulkner, Microstructural control of maraging steel C300, Mater. Sci. Tech. Lond. 27 (2011) 395-405.

[32] EOS Maraging Steel MS1 http://ip-saas-eos-cms.s3.amazonaws.com/public/ 1af123af9a636e/042696652ecc69142c8dc772dc/EOS MaragingSteel_MS1_en.pdf.

[33] C. Sanz, V.G. Navas, Structural integrity of direct metal laser sintered parts subjected to thermal and finishing treatments, J. Mater. Process Technol. 213 (2013) 2126-2136.

[34] D.R. Lide, CRC Handbook of Chemistry and Physics, Internet Version, 87th edition, Taylor and Francis, Boca Raton, FL, 2007 http:/www.hbcpnetbase.com.

[35] N. Kang, W.Y. Ma, F.Y. Li, H.L. Liao, M. Liu, C. Coddet, Microstructure and wear properties of selective laser melted WC reinforced $18 \mathrm{Ni}-300$ steel matrix composite, Vacuum (2018), http://dx.doi.org/10.1016/j.vacuum.2018.04.044.

[36] F.Z. Li, Z.M. Wang, X.Y. Zeng, Microstructures and mechanical properties of Ti6Al4V alloy fabricated by multi-laser beam selective laser melting, Mater. Lett. 199 (2017) 79-83.

[37] Y.D. Jia, P. Ma, K.G. Prashanth, G. Wang, J. Yi, S. Scudino, F.Y. Cao, J.F. Sun, J. Eckert, Microstructure and thermal expansion behavior of Al-50Si synthesized by selective laser melting, J. Alloys Compds 699 (2017) 548-553.

[38] G. Kasperovich, J. Haubrich, J. Gussone, G. Requena, Correlation between porosity and processing parameters in TiAl6V4 produced by selective laser melting, Mater Des. 105 (2016) 160-170.

[39] R.K. Enneti, R. Morgan, S.V. Atre, Effect of process parameters on the selective laser melting (SLM) of tungsten, Int. J. Refract. Met. Hard 71 (2018) 315-319.

[40] A. Iveković, N. Omidvari, B. Vrancken, K. Lietaert, L. Thijs, K. Vanmeensel, J. Vleugels, J.P. Kruth, Selective laser melting of tungsten and tungsten alloys, Int J. Refract. Met. Hard 72 (2018) 27-32.

[41] K. Kempen, E. Yasa, L. Thijis, J.P. Kruth, J.V. Humbeeck, Microstructure and mechanical properties of selective laser melted 18Ni-300 steel, Phys. Procedia 12 (2011) 255-263.

[42] G. Cacciamani, A. Dinsdale, S. Palumbo, The Fe-Ni (iron-nickel) system: thermaldynamical modeling assisted by atomistic calculations, Intermetallics 18 (2010) 1148-1162.

[43] T. Rong, D.D. Gu, Q.M. Shi, S.N. Cao, M.J. Xia, Effects of tailored gradient interface on wear properties of WC/Inconel 718 composites using selective laser melting, Surf. Coat. Tech. 307 (2016) 418-427.

[44] J. Suryawanshi, K.G. Prashanth, S. Scudino, J. Eckert, O. Prakash, U. Ramamurty, Simultaneous enhancements of strength and toughness in an Al-12Si alloy synthesized using selective laser melting, Acta Mater. 115 (2016) 285-294.

[45] L. Thijs, J. Humbeeck, K. Kempen, E. Yasa, J.P. Kruth, M. Rombouts, Investigation on the inclusions in maraging steel produced by selective laser melting, Innovative Developments in Virtual and Physical Prototyping, (2011), pp. 297-304.

[46] N. Kang, P. Coddet, L. Dembinski, H. Liao, C. Coddet, Microstructure and strength analysis of eutectic Al-Si alloy in-situ manufactured using selective laser melting from elemental powder mixture, J. Alloys Compd. 691 (2017) 316-322. 